JOURNAL

of Health Inequalities

\title{
Tackling the COVID-19 pandemic through governmental regulations: the experience of Poland
}

\author{
Lukasz Gruszczynski \\ Kozminski University, Warsaw, Poland \\ Centre for Social Sciences - Institute for Legal Studies, Budapest, Hungary
}

\begin{abstract}
The article presents a summary of the research results of the project on the development of the COVID-19 pandemic in Poland in its initial phase (March-June 2020). It argues that the design and timing of regulatory responses, as well as the adherence of the population to the relevant rules, had a critical impact on the progression and public health consequences of the pandemic. On that basis, the article concludes that well-designed public health measures, which are implemented early as a part of the proactive strategy that anticipates and reacts quickly to changing circumstances can effectively decrease number of COVID-19 infections and related deaths, provided that adherence of a relevant population is high.
\end{abstract}

KEY WORDS: COVID-19, Poland, excess deaths, public health and regulation, pandemic.

ADDRESS FOR CORRESPONDENCE: Lukasz Gruszczynski Assoc. Prof., Kozminski University, 57/59 Jagiellonska St., 03-301 Warsaw, Poland, e-mail: Igruszczynski@kozminski.edu.pl

When the COVID-19 pandemic hit Europe in Winter 2020, it followed distinctive trajectories in different parts of the European Union (EU). Most of the Western Members saw in the first phase of the pandemic surging numbers of both cases and COVID-19-related deaths, which started to slowly decline only after weeks of exponential growth. On the other hand, their neighbors from Central-Eastern Europe (CEE) experienced much milder progressions of the pandemic. For example, the number of officially registered cases and deaths (per 1 million inhabitants) in the first five months (counted from the date when the first local transmission was detected) were the following: Slovakia - 29/5, Hungary - 478/55, Poland - 1,370/47, Czechia - 1,637/36. These figures were much lower than in Western Europe, where France recorded 2,515/463, Germany - 2,319/98, Spain - 5,832/606, while the United Kingdom (UK) - at that time already outside the EU - 4,109/591 [1]. Although, there are significant differences between the Western and CEE parts of the EU when it comes to COVID-19 testing (in general countries such as Poland, Hungary and Czechia have performed fewer tests), the dynamic was clearly different, the fact that is confirmed by the data on excess deaths in the covered period. In particular, none of the CEE mem- bers of the EU witnessed in the initial phase of the pandemic any significant divergences from their long-term trends in population mortality rates, which was the case in all West European countries.

To many this came as a real surprise as one could have expected just the opposite. The CEE Member States have generally weaker public healthcare systems than their Western peers. This is true not only when it comes to infrastructure, but more importantly available human resources. For example, Poland - the largest country of the region - has just 2.4 physicians per 1.000 inhabitants. This is a significantly lower number than the EU average (3.7), with the EU leaders, such as Germany or Austria, being well above 4 [2]. The same is true for practicing nurses per 1.000 inhabitants, as Poland has merely 5.2 as compared to the EU average of 8.4 [3]. All the countries of Central Europe also rank lower than their Western peers in the Global Health Security Index, which measures health security capabilities, showing the preparedness of states for the pandemic. Poland's score is 55.4 and Hungary's is 54, while Slovakia is only 47.9. The situation looks different in the Western Europe, with Germany having a score of 66, France 68.2, Spain 65.9 and the UK $77.9[4]$. 
Various hypotheses have been put forward to explain the differences in the development of the epidemic among countries around the globe. For example, it has been argued that the existence of compulsory BCG vaccination programmes may have had an impact on the spread and mortality rates of COVID-19 [5]. The relevant research is however still at a very preliminary stage, and its results remain at best contradictory [6]. Some have also pointed to the demographic structures of the countries [7], the population density and connectivity, as well as various cultural factors relating to the character and intensity of social contacts.

It is rational to assume that some of these contextual factors could have slowed down the initial spread of COVID-19 in the CEE region, limiting the number of new infections and preventing deaths in overloaded hospitals. However, as we argue in the forthcoming article, coauthored with Mateusz Zatoński and Martin McKee [8], what really appears to have mattered was the design and timing of the regulatory response to the pandemic taken by the CEE governments as well as the adherence of the respective population to the new restrictions. We have used Poland as a specific case study to test that hypothesis.

After reviewing the relevant data, we have found that Poland was very quick in enacting a series of very strict public health measures designed to limit the spread of the virus. The country effectively instituted a comprehensive lockdown within 18 days of the first diagnosed coronavirus case and 14 days from the first local transmission. While most of the West European countries eventually introduced lockdowns, they did so much later, when the epidemic was already well-advanced on their territories. In several respects the Polish government actually decided to go beyond international good practice and apply measures that were not recommended by international institutions and the effectiveness of which only became acknowledged later. For example, obligatory face masks in public places were introduced in Poland almost two months earlier than the recommendation of the World Health Organization. Although the ultimate strictness was very similar for all investigated European states (as measured by the Government Response Stringency Index developed by the scientists from the University of Oxford), Poland not only reacted earlier than the Western countries, but also moved quicker from an unrestricted regime to a rigorous one. It took the country only 21 days from the detection of its first case of local transmission to move from almost no restrictions to a very strict sanitary regime (as compared to 47 days in France and 34 days in Spain).

Despite the limited trust of Poles in public institutions and the generally ineffective enforcement mechanisms (at least in terms of their perception by the population), the actual adherence seems to have been relatively high. Again, if one looks at the data on the usage of face masks, it appears that the level of adherence was much higher in Poland than in Western Europe. The relevant figure reached $78 \%$ (on 29 April 2020) and remained above $70 \%$ for more than a month (between 14 April and 21 May 2020). In France the maximum level was 44\% (24 May - 8 June 2020), the UK reached only 13\% (16 June and later), while Germany recorded 52\% (24 May 2020 and later). Spain was the best performer, reaching $79 \%$ on 13 June 2020, but this was almost two months later than a similar level was recorded in Poland [9].

Our conclusions, insofar as they concern the central role of regulatory intervention in limiting the size of the COVID-19 outbreak in Poland in its initial phase, are further reinforced by the subsequent developments in the later stages of the pandemic. As of 19 April 2021, Poland has officially registered 2,695,327 cases and 62,133 COVID-19 related deaths [1]. In early November Poland actually surpassed Spain and the UK in new daily confirmed cases of COVID-19 per million inhabitants (as a rolling 7-day average) [10], while on 21 November 2020, despite relatively low levels of testing, it had the second highest number of confirmed infections per 100,000 inhabitants in the EU, just behind Italy. Considering that the cases have been significantly underreported in Poland, their real number is much higher. A similar situation occurred in spring 2021 when Poland was one of the most affected countries in the EU. The more objective picture is visible when one looks at the excess death rates. Poland recorded the EU's highest rate in 2020 (20.25\%), with most of the additional deaths between September and December [11]. This shows that the virus was much widespread, while the true death toll was significantly higher than the official data indicate [12]. In this context, it should be noted that none of the contextual and structural factors (i.e. demographic structure, population density/connectivity and cultural factors) have changed. What has changed are three regulatory components that characterised Poland's initial, successful response to COVID-19. Most of the restrictions in Poland were either withdrawn or watered down between May and June 2020. These modifications were introduced not only to restart the economy and limit the associated economic crisis, but also due to political reasons connected with the planned presidential election at the end of June 2020. As the number of cases began to grow in Poland, in September 2020 restrictions were re-introduced. However, this time they were implemented more slowly than in other EU countries, and much more slowly than during the first phase of the pandemic in Poland. The adherence of Poles to public health measures also deteriorated over the summer. While Poland was not the only European country to experience what has been termed as "pandemic fatigue" [13], the decline in adherence to restrictions appears to have been greater in Poland than in other EU countries.

All of these observations have led us to the conclusion that the mild progression of the COVID-19 in 
Poland during its first phase can be attributed to the swift and strict interventions of the government and high adherence of the population, while the delayed and insufficient regulatory response to the second phase of the crisis, combined with limited adherence of Poles to the new restriction, have been the main factors behind the subsequent - and current - public health crisis in Poland.

\section{DISCLOSURE}

The author reports no conflict of interest.

\section{References}

1. Reported Cases and Deaths by Country or Territory, Covid-19 (own calculations by the author). Available from: https://www. worldometers.info/coronavirus/ (accessed: 19 April 2021).

2. Physicians (per 1,000 people) - European Union. WHO Global Health Workforce Statistics, OECD, supplemented by country data, 2016-2017. Available from: https://bit.ly/3gxFsvT (accessed: 19 April 2021)

3. OECD \& European Commission, Health at a Glance: Europe 2018. State of Health in the EU Cycle, 2019, p. 181. Available from: https://www.oecd.org/health/health-at-a-glance-europe/ (accessed: 19 April 2021).

4. GHS Index Map (The index is composed of six categories that fall under the following labels: prevention, detection and reporting, rapid response, health system, compliance with global norms, and risk environment). Available from: https:// www.ghsindex.org (accessed: 19 April 2021).

5. Klinger D, Blass I, Rappoport N, Linial M. Significantly improved COVID-19 outcomes in countries with higher BCG vaccination coverage: a multivariable analysis. Vaccines 2020; 8(3): 378 .

6. Hamiel U, Kozer E, Youngster I. SARS-CoV-2 rates in BCG-vaccinated and unvaccinated young adults. JAMA 2020; 323(22): 2340-2341.

7. Duszyński J, Afelt A, Ochab-Marcinek M, et al. Zrozumieć Covid-19 [Understanding Covid-19]. PAN, 2020. Available from: https://informacje.pan.pl/images/2020/opracowanie-covid19-14-09-2020/ZrozumiecCovid19_opracowanie_PAN.pdf (accessed: 19 April 2021).

8. Gruszczynski L, Zatoński M, McKee M. Do regulations matter in fighting the COVID-19 pandemic? Lessons from Poland (27 January 2021). Available from: https://ssrn.com/ abstract=3786076 or http://dx.doi.org/10.2139/ssrn.3786076 (accessed: 19 April 2021)

9. The Institute for Health Metrics and Evaluation (IHME), COVID-19 Projections. Available from: http://www.healthdata.org (accessed: 19 April 2021).

10. Statistics and Research. Coronavirus Pandemic (Covid-19). Available from: https://ourworldindata.org/coronavirus (accessed: 19 April 2021)

11. Eurostat, Deaths by week and sex $(2016-2019,2020)$. Available from: https://ec.europa.eu/eurostat/databrowser/view/demo_ mmonth/default/table?lang=en (accessed: 19 April 2021).
12. Zatoński W, Janik-Koncewicz K. Dziesiątki tysięcy dodatkowych zgonów. Menedżer Zdrowia (3 February 2021). Available from https://www.termedia.pl/mz/Dziesiatki-tysiecy-dodatkowych-zgonow,41248.html (accessed 19 April 2021).

13. Pandemic fatigue. Reinvigorating the public to prevent COVID-19. WHO, 2020. Available from: https://apps.who. int/iris/bitstream/handle/10665/335820/WHO-EURO-20201160-40906-55390-eng.pdf (accessed: 19 April 2021). 